\title{
Using Analytic Hierarchy Process to Examine the Success Factors of Autonomous Landscape Development in Rural Communities
}

\author{
Ta-Ching Liang ${ }^{1}$ and Szu-Hsien Peng ${ }^{2, *}$ \\ 1 Department of Leisure and Recreation, National Formosa University, Yunlin 632, Taiwan; \\ taching@nfu.edu.tw \\ 2 Department of Spatial Design, Chienkuo Technology University, Changhua 500, Taiwan \\ * Correspondence: shpeng@cc.ctu.edu.tw; Tel.: +886-4-711-1111 (ext. 2256) \\ Academic Editor: Tan Yigitcanlar \\ Received: 15 March 2017; Accepted: 28 April 2017; Published: 2 May 2017; Corrected: 25 February 2022
}

\begin{abstract}
The absence of comprehensive plans has resulted in disordered rural development and construction and a mix of new and old buildings in rural communities. Disorganized and blighted spaces have become rural landscape obstacles. After the Rural Rejuvenation Act was passed, rural construction has been guided with plans, and the government expects to enhance surroundings and expand policies through autonomous community development to create a good rural landscape. Through a literature review, this study aims to establish key success factors in autonomous landscape development of rural communities, covering 8 criteria and 28 sub-criteria. A questionnaire survey was conducted among national rural communities, experts, and scholars. The analytic hierarchy process reveals that manpower input has the highest importance, thereby indicating that the improvement of autonomous community development would double with the guidance of community cadres and the participation of artists and experts.
\end{abstract}

Keywords: rural aesthetics; autonomous development; analytic hierarchy process

\section{Introduction}

Rural communities are places for agricultural production and village life. However, with changes in socioeconomic structure, rural functions are unable to meet the requirements of modern development [1]. Rural emigration has resulted in a large age gap and an urban-rural gap, which has worsened the modern living environment, landscape ecology, and appearance of rural communities. Community residents discarded junk or waste in outdoor spaces and ignored the management of public spheres, thereby resulting in a poor visual landscape in communities [2,3]. Blighted buildings and discarded refuse were rampant and caused communities to look dilapidated, and community residents have become immune to such waste. The broken windows theory was presented to explain the rise of waste and idle space in communities [4,5].

The problem of blighted space in rural communities has worsened in Taiwan, prompting rural communities to search for solutions. Since the promulgation of the Rural Rejuvenation Act on 4 August 2000, the relevant sub-regulations, and the rural rejuvenation fund, 4000 rural communities in Taiwan have been targeted for revitalization. The Act stresses the promotion of rural communities with the characteristic of an agricultural living environment. On the basis of the Rural Rejuvenation Act, regulations on landscape public space improvement, community ecological preservation and maintenance, historical survey and preservation, and industrial revitalization are organized into executable items for rural communities. Guidelines and promotion strategies are presented for the improvement and construction of rural communities under rural rejuvenation in areas of jurisdiction. 
The idea of rural construction and the principle of autonomous promotion of aesthetics are introduced to improve agricultural production and sales, enhance rural residents' quality of life, and reduce rural ecological and environmental problems and the urban rural gap. For this reason, the autonomous development experiences and methods of model communities are studied to discuss the key success factors and assist communities in improving their environment. The growth of community residents in the autonomous development process is another motivation for this study.

Autonomous development aims to help communities work together and participate through self-organization, design, and communication. Although the entire process is implemented by community residents, subsidies and counsel are available from municipalities or county (city) authorities for local organizations and community development associations in Taiwan. Relevant promotion policies in the USA, Germany, and Japan are analyzed, as shown in Table 1.

Table 1. Introduction of promotion policies in different countries.

\begin{tabular}{|c|c|c|}
\hline Nation & Year & Policy \\
\hline \multirow{5}{*}{ USA } & 1960 & $\begin{array}{l}\text { 1. } \\
\text { 2. } \\
\text { 3. } \\
\text { 4. } \\
\text { 4ain street plations in low-income villages and defense rules } \\
\end{array}$ \\
\hline & 1966 & $\begin{array}{l}\text { The National Historic Preservation Act was passed and subsequently revised } \\
\text { in } 1992\end{array}$ \\
\hline & 1974 & $\begin{array}{l}\text { The Community Coordinated Development Subsidies Act was passed, } \\
\text { which was one of the largest subsidy plans promoted by the federal } \\
\text { government of the United States }\end{array}$ \\
\hline & 1977 & Community Reinvestment Act \\
\hline & 1994 & Overall urban planning \\
\hline \multirow{2}{*}{ Germany } & 1971 & Urban development support plan \\
\hline & 1976 & Drafting rural regeneration \\
\hline \multirow{2}{*}{ Japan } & 1988 & Act of 0.1 billion yen to create the life of hometown \\
\hline & 2000 & Historical blocks and settlement conservation charter \\
\hline \multirow{3}{*}{ Taiwan } & 1968 & The Ministry of the Interior promulgated Community Development Framework \\
\hline & 1994 & The Ministry of Culture proposed Community Building \\
\hline & 2010 & Rural Regeneration Plan \\
\hline
\end{tabular}

Table 1 shows the distinct development background and factors in different countries. Such policies were expected to arouse community residents' awareness. Community residents in different countries would participate in the strategies promoted by the governments with the rights and interests of communities in mind. Nevertheless, the operation was mainly guided by communities to gradually expand the spirit of autonomous development. The plan execution, policy promotion, and relevant regulations in Japan and Taiwan were similar, possibly because the promotion policies in Taiwan originated from Japan and the execution model and relevant regulations were formulated by referring to those in Japan.

Peasants in Taiwan began to participate in the government's construction mainly under the auspices of the "Community Development Framework" promulgated by the Ministry of the Interior in 1968. However, actual development in Taiwan was put forward in a policy called "Community Building", proposed by the Ministry of Culture in 1994. Since the first bottom-up participation of residents in community development in 1994, the government has also made a considerable investment in manpower and material resources and guided the community to perform community construction for around 
16 years, up until the advent of the Rural Regeneration Plan in 2010. In these periods, the government invested much manpower and material resources as well as a considerable amount of financial resources.

By collecting and analyzing research [6-9] on the autonomous development of rural communities and rural aesthetics [10-15], this study intends to explore the benefits of autonomous development for space improvement in rural communities. Gladkova and Romero-Trillo [16] discovered that beauty was composed of evaluation, emotion, and perception. Liu [17] pointed out that style beauty, artistic beauty, and implication beauty are the compositions of excellent landscape works, as they presented the aesthetic structure of the surface, middle, and deep layers. Rural landscape versus urban landscape-including landscape change and the urbanization process—-was studied by Antrop [18,19]. Hsu and Sun [20] described the differences between rural and urban landscapes. Rural areas contain rich natural resources, such as mountains, water, farms, and plantations, whose natural colors were different from those in the urban environment. Humans were drawn to and could easily accept natural colors. Relevant research [21-26] covers various factors in the rural landscape. Thus, eight dimensions-namely, rural families, farmers, rural industries, green villages, hydropower resources, leisure and recreation, rural art, and rural history-are regarded as the compositions of rural landscape in this study.

Unlike traditional space constructed by offices and construction companies, autonomous development refers to the space change and construction process to stimulate local public and private sectors to develop a new partnership. Communities re-establish community workers through employment and cooperate with experts and residents to maintain the interaction with the living environment. Instead of randomly applying standard materials, construction materials that are suitable for local aesthetics are purchased [27]. Wang and Zhai [28] regarded employment and purchase as the practice of participatory design to pass down traditional work skills and implement local aesthetics by the residents who understand and participate in the construction of community space.

Since 2009, the Taiwan Soil and Water Conservation Bureau has registered local organizations or groups in rural communities who have undergone counseling and participated in manpower training to propose plans for employment and purchase. The work covers environmental improvement and green landscaping, repurposing of space, and recovery of rural characteristic buildings. The budget is subsidized, and communities have to raise at least $10 \%$ matching grants. Employment and purchase are still new in Taiwan, and thus, many difficulties in the execution process still exist.

Employment and purchase assist communities in reusing the space to create community characteristics in finding local talents with professional skills to create more employment opportunities, and in adhering to community consensus through discussion. Rural areas in Taiwan could develop independently through a series of steps to achieve autonomous development $[29,30]$. Employment and purchase is divided into pre-stage, planning and design, construction, acceptance verification, maintenance and management, and extension.

The real meaning of community development is gradually revealed when community organization and development associations achieve community status and define self-value through the autonomous development process. The core of a community is similar to that of a miniature society. A complete society is supported by a powerful structure, and a community is the same. This study focuses on the factors in communities that are beautifying blighted and idle space through autonomous development to promote the local environment. The following four research objectives are discussed in this study:

- With the use of the analytic hierarchy process (AHP), key success factors in improvement are identified for communities to develop positive meanings in future promotion.

- Through a questionnaire survey among community cadres and residents of good communities, the weights of key success factors in the construction of blighted space are acquired.

- The understanding and opinions of experts and scholars and participants with regard to key success factors are compared, and the weight difference and the factors are compared for communities that seek to improve blighted spaces in the future.

- The analysis of key success factors could serve as a reference for communities that aim to achieve autonomous development and practice community development. 
Blighted space is a common dilemma in rural areas in Taiwan and influences the living environment and farmers' health. With the guidance of the Rural Rejuvenation Act, the government, by turning obstacles into benefits, subsidizes the autonomous action of communities to correspond to the philosophy of deduction, which could enhance the entire landscape, prioritize the elimination of cluttered places, avoid excessive hardware design, and focus on environmental improvement and green landscaping [28,31-35]. Moreover, living settlements could provide the most benefit to residents through enhanced quality of life with the improvement of the environment.

The development of rural communities is closely related to agricultural development, and the use of agricultural resources that serve as effective participation mechanisms for rural community development needs to be established to facilitate cohesion among community residents. On the basis of the geographical conditions of local communities, community leaders could actively execute development plans to inspire local residents' interest in farming and develop local characteristics of the community. Feasible resource raising and application could be taken into account, and local civil organizations, enterprises, and schools could join the development.

The dimensions, categories, and weights of success factors in autonomous landscape development in rural communities are established after confirming the research objective, collecting relevant literature, and interviewing experts. The importance of dimensions and success factors in autonomous landscape development in rural communities is further studied for analysis. The management significance of the results and conclusions is proposed.

\section{Research Methodology}

AHP is used for communities that practice autonomous development (Figure 1) [36-39]. AHP, which is a decision-making method with multiple goals or standards, aims to divide complicated and unstructured problems into several groups and organize them into hierarchies. Then, the opinions of experts and scholars and various hierarchies that actually participate in decision-making to simplify complex systems are organized into a simple hierarchic system. The nominal scale is regarded as the pairwise comparison of the elements in different hierarchies. After establishing the pairwise comparison matrix, the eigenvector of the matrix is calculated, and the priority vector of the hierarchy is decided according to the eigenvector to represent the priority of elements. The eigenvalue is then calculated to evaluate the consistency of the pairwise comparison matrix as the decision evaluation indicator. AHP consists of six processes: identification of the evaluation factors, construction of hierarchical structure, establishment of the dual matrix, solving the eigenvalue and eigenvector, consistency test of the dual matrix, and solving the dominant proportion of factors, which are explained below.

\subsection{Problem Definition}

The system with problems should be expanded, and the possible factors should be included in the problems. A planning group is established to define the scope of the problems.

\subsection{Establishment of the Hierarchical Structure}

The members in the planning group would brainstorm to determine the evaluation, sub-evaluation, and bottom criteria that affect problem behaviors to form a hierarchical structure. According to Saaty [40], assuming that $n$ factors exist in a complicated problem, total $C_{2}^{n}=n(n-1) / 2$ pairwise comparison is required.

\subsection{Questionnaire Design and Survey}

The nominal scale is used for the comparison in AHP. The nominal scale is divided into nine hierarchies from "equal importance" to "absolute importance", which are weighted from 1 to 9 . The elements in each hierarchy are subjected to pairwise comparison and sequenced according to importance in AHP to understand the evaluators' subjective opinions. The elements in the previous hierarchy are used as the evaluation criteria for the pairwise comparison. According to 
the principle and meaning of the evaluation scale in AHP, problems in each pairwise comparison are included in a questionnaire for decision makers or decision-making groups. The problems in each pairwise comparison should be clearly described with detailed guidance and explanation. A pairwise comparison matrix is established according to the questionnaire survey result, and the eigenvalue and eigenvector are further calculated with analysis tools. Meanwhile, the matrix consistency is tested. When the matrix consistency does not correspond to the request, the judgment of the decision makers is inconsistent. The researcher has to clearly explain the questions to the decision makers. The scale used for the pairwise comparison is listed in Table 2.

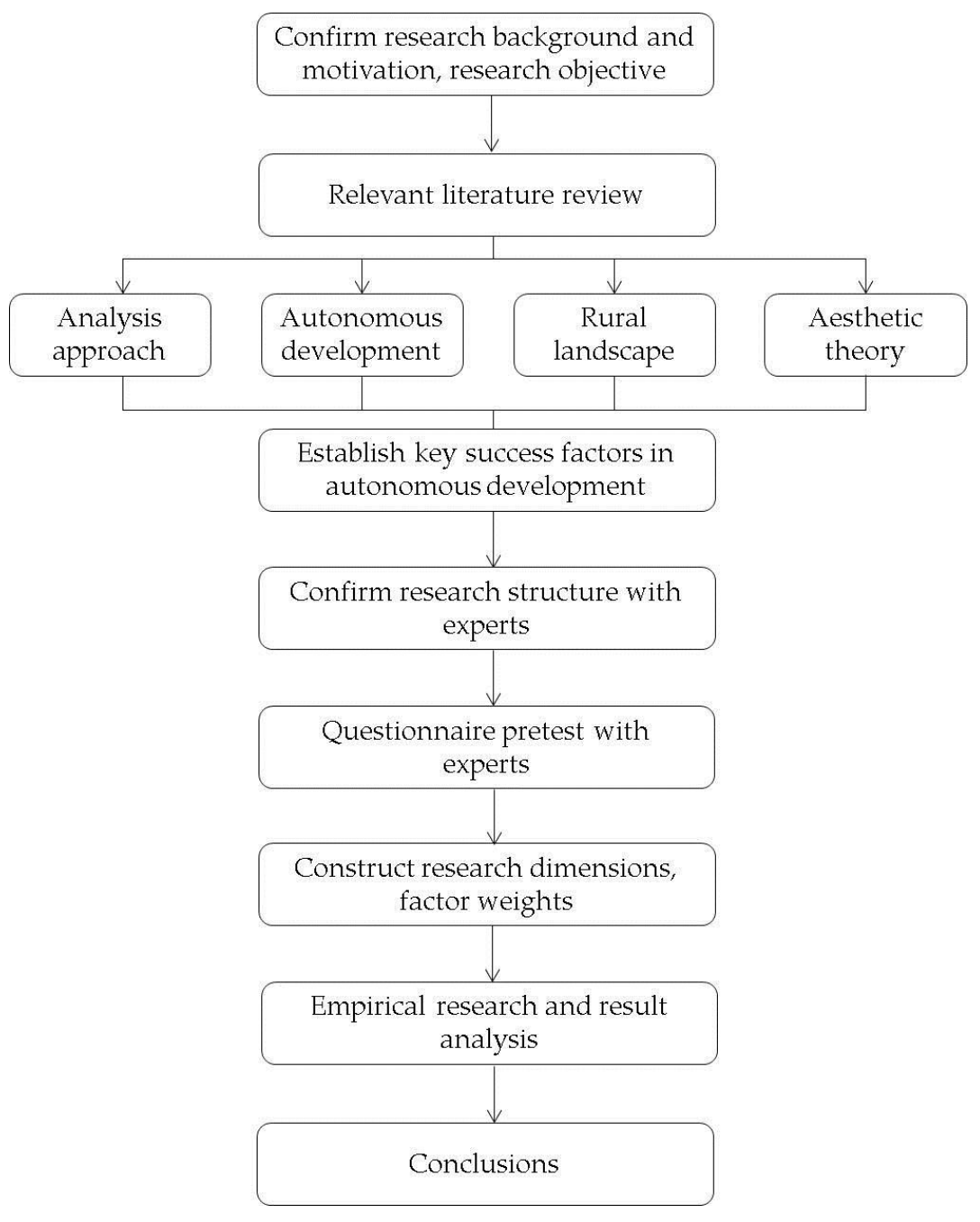

Figure 1. Research flowchart.

Table 2. Definition and description of analytic hierarchy process (AHP) evaluation scale.

\begin{tabular}{|c|c|c|}
\hline Evaluation Scale & Definition & Description \\
\hline 1 & Equal importance & $\begin{array}{l}\text { The evaluation potential of two comparison conditions presents } \\
\text { equal importance. (equal) }\end{array}$ \\
\hline 3 & Weak importance & $\begin{array}{l}\text { Judging from experiences, it slightly tends to the first evaluation } \\
\text { condition. (moderately) }\end{array}$ \\
\hline 5 & Essential importance & $\begin{array}{l}\text { Judging from experience, it tends somewhat to the first } \\
\text { evaluation condition. (strongly) }\end{array}$ \\
\hline
\end{tabular}


Table 2. Cont.

\begin{tabular}{ccl}
\hline Evaluation Scale & \multicolumn{1}{c}{ Definition } & \multicolumn{1}{c}{ Description } \\
\hline 6 & Evaluation score between 5 and 7 & When a compromise value between 5 and 7 is required. \\
\hline 7 & Very strong importance & $\begin{array}{l}\text { Extremely strong intention to the first evaluation condition. } \\
\text { (very strong) }\end{array}$ \\
\hline 8 & Evaluation score between 7 and 9 & When a compromise value between 7 and 9 is required. \\
\hline 9 & Absolute importance & It absolutely tends to the first evaluation condition. (extremely) \\
\hline
\end{tabular}

\subsection{Establishment of Pairwise Comparison Matrix}

On the basis of the elements in the previous hierarchy as the evaluation standard of the element in a hierarchy, pairwise comparison among elements is performed to determine the relative importance between two elements. With the nominal scale, the relative importance ratio is set with the values of $1 / 9,1 / 8, \ldots, 1 / 2,1,2,3, \ldots, 8,9$. The pairwise comparison result is placed in the upper triangle of the pairwise matrix. The main diagonal is the comparison of the elements, with a value of 1 . The lower triangle is the reciprocal of the upper triangle and is the pairwise comparison matrix $\mathbf{A}$, as shown below.

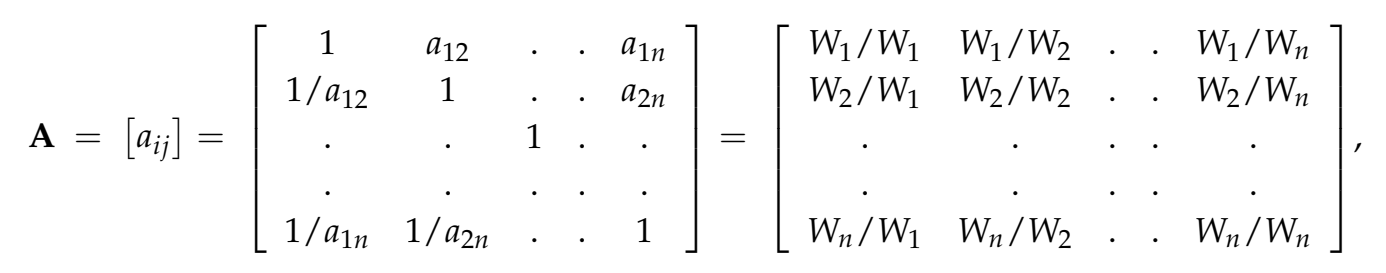

where $a_{i j}$ stands for the cross comparison of decision factors $i$ and $j$, as the importance of decision factors $i$ and $j$ for decision makers. The weights of elements in different hierarchies are then calculated after acquiring the pairwise comparison matrix. The common eigenvalue solution in numerical analysis is used to determine the eigenvector or dominant vector and the maximum eigenvalue of the pairwise comparison matrix. As a pairwise comparison matrix is a positive reciprocal matrix and not a symmetric matrix, the power and the householder methods are used for the eigenvalue solution. The eigenvector in this study is directly calculated with AHP. The maximum eigenvalue and eigenvector are calculated with the following equation:

$$
W_{i}=\frac{1}{n} \sum_{i=1}^{n} \frac{a_{i j}}{\sum_{i=1}^{n} a_{i j}}
$$

The pairwise comparison matrix $\mathbf{A}$ is first multiplied by the calculated eigenvector $W_{i}$ to acquire a new vector $W_{i}{ }^{\prime}$, and then the average multiple of the two is the maximum eigenvalue $\lambda_{\max }$, which is shown as follows:

$$
\begin{aligned}
W_{i}^{\prime}=\mathbf{A} \times W_{i}= & {\left[\begin{array}{ccccc}
W_{1} / W_{1} & W_{1} / W_{2} & \cdot & \cdot & W_{1} / W_{n} \\
W_{2} / W_{1} & W_{2} / W_{2} & \cdot & \cdot & W_{2} / W_{n} \\
\cdot & \cdot & \cdot & \cdot & \cdot \\
\cdot & \cdot & \cdot & \cdot & \cdot \\
W_{n} / W_{1} & W_{n} / W_{2} & \cdot & \cdot & W_{n} / W_{n}
\end{array}\right]\left[\begin{array}{c}
W_{1} \\
W_{2} \\
\cdot \\
\cdot \\
W_{n}
\end{array}\right]=\left[\begin{array}{c}
W_{1}^{\prime} \\
W_{2}^{\prime} \\
\cdot \\
\cdot \\
W_{n}^{\prime}
\end{array}\right] } \\
& \lambda_{\max }=\left(\frac{1}{n}\right)\left(\frac{W_{1}^{\prime}}{W_{1}}+\frac{W_{2}^{\prime}}{W_{2}}+\ldots+\frac{W_{n}^{\prime}}{W_{n}}\right)
\end{aligned}
$$

\subsection{Consistency Test}

In AHP, consistency index (C.I.) and consistency ratio (C.R.) are applied to measure the consistency of the pairwise comparison matrix. Numerous hierarchies and elements are judged. Therefore, achieving pairwise comparison consistency is difficult for the respondents. The pairwise 
comparison matrix value is therefore subjected to the consistency test to test the consistency of the pairwise comparison matrix constructed by the questionnaire respondents. In addition to the consistency test of hierarchies, the consistency of the entire hierarchical structure is tested. Saaty suggested the use of C.I. and C.R. to test the consistency of the pairwise comparison matrix, and the C.R. in various hierarchies or the entire hierarchical structure should be $<0.1$ to prove the consistency and rationality of the respondents' judgment.

Saaty proposed four approximate approaches of line vector mean standardization, row vector mean standardization, line vector and reciprocal standardization, and row vector geometric mean standardization to calculate the eigenvalue and eigenvector of the comparison matrix. The C.I. is calculated as follows:

$$
\text { C.I. }=\frac{\lambda_{\max }-n}{n-1}
$$

where $\lambda_{\max }$ is the maximum eigenvalue and $n$ is the number of evaluation criteria.

The consistency test could be used to judge evaluators and the entire hierarchical structure. To ensure consistency, Saaty [41] suggested the best C.I. $<0.1$ and the maximum acceptable error C.I. $<0.2$. When C.R. $<0.1$, the pairwise comparison matrix consistency was satisfactory; otherwise, the pairwise comparison matrix consistency did not achieve the acceptable reliability. The evaluation value in the pairwise comparison matrix should be rationally modified and adjusted to reduce the risk of respondents' subjective misjudgment.

\subsection{Option}

The overall hierarchical weight is calculated after calculating the element weights in various hierarchies. When the hierarchical structure is consistent, the dominant vector of criteria could be calculated. When only a decision maker is considered, the comprehensive criterion evaluation is calculated. When a decision-making group is considered, the comprehensive criterion evaluation of each decision-making member is calculated separately. Geometric mean is then utilized to calculate the weighted evaluation to decide the relative importance and priority of the criteria.

\subsection{Questionnaire Design}

This study aims to discuss key success factors in the autonomous development of rural communities through AHP. With regard to the establishment of the AHP structure, domestic research on key success factors in autonomous community development is used as reference, and the structure for this study is shown in Figure 2.

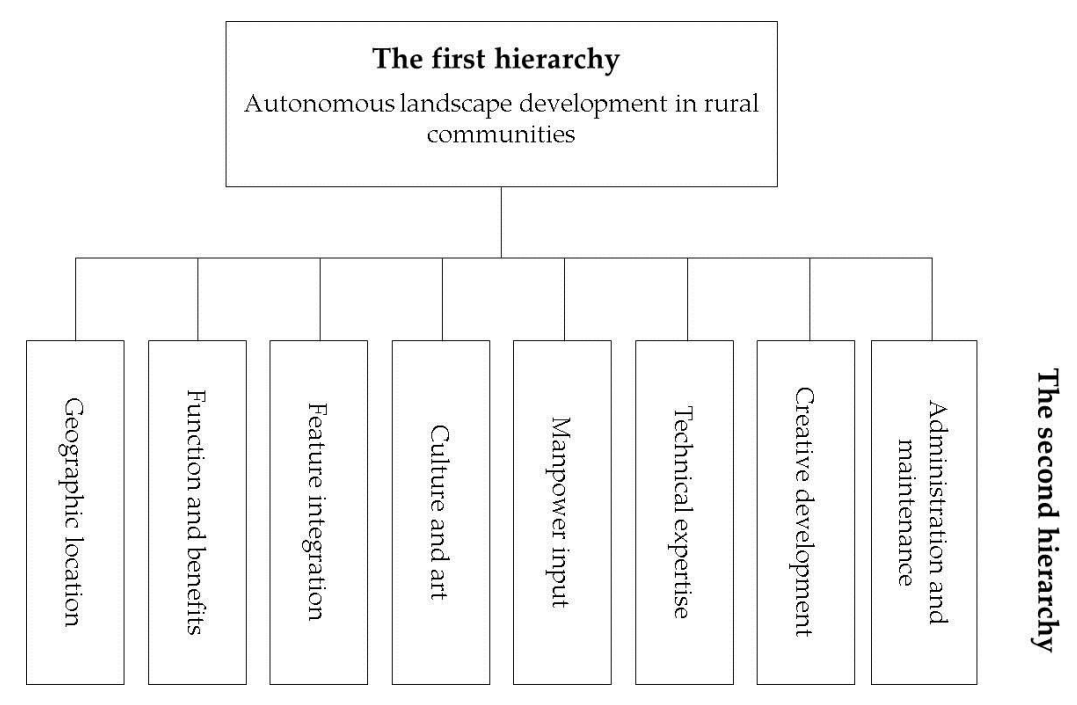

Figure 2. Research framework. 
Factors in the first hierarchy are the so-called "success factors", which are defined as "factors in autonomous community development" on the basis of which the second and the third hierarchies are developed. After organizing the relevant research, the second hierarchy of AHP is preliminarily divided into geographic location, function and benefits, feature integration, culture and art, manpower input, technical expertise, creative development, and administration and maintenance. According to the above factors, the various research variables of the second hierarchy are further developed into 28 success factors of the hierarchy as follows:

(1) Geographic location

i. Comprehensive planning: Locations for autonomous development improvement are considered in the rural rejuvenation plan.

ii. Development priority: Locations are the priority for community development improvement in this study.

iii. Scenic spot concatenation: Locations for autonomous development improvement could be linked with scenic spot concatenation around communities.

iv. Located in settlement: Autonomous development improvement is within the core settlement in communities.

(2) Function and benefits

i. Interior consensus: Thorough discussions are conducted internally prior to implementing autonomous development.

ii. Landscaping: The green landscaping is satisfactory after improving the original location.

iii. Functioning: The originally estimated function is developed after the autonomous development improvement.

iv. Surrounding residents and visitors could use the space after the autonomous development improvement.

(3) Feature integration

i. Performance focus: The content of autonomous development conforms to the local development focus of rural communities.

ii. Cultural integration: Autonomous development integrates with local culture.

iii. Feature display: The autonomous development outcome could build local uniqueness.

(4) Culture and art

i. Cultural connotation: Autonomous development could integrate with community history and culture.

ii. Art show: Autonomous development is the presentation of local art.

iii. Skill heritage: Skilled seniors (masters) would teach young people to ensure collaborative construction in the process.

(5) Manpower input

i. Leading cadre: Community cadres would guide the work direction during autonomous development.

ii. Art expert: Community artists or technical masters would collaboratively participate in autonomous development.

iii. Workman implementation: Construction workers or technicians in communities would collaboratively participate in autonomous development. 
iv. Volunteer participation: Volunteers would collaboratively participate in autonomous development.

(6) Technical expertise

i. Skilled technique: Autonomous development constructors present skilled techniques.

ii. Construction quality: Autonomous development construction shows excellent quality and is good to use.

iii. Ancient technique integration: Traditional skills or work is integrated into autonomous development construction.

(7) Creative development

i. Local material: Local materials are used for autonomous development.

ii. Recycle and reuse: Waste and recycled materials are applied to autonomous development.

iii. Creative development: Special creativity and invention are utilized for autonomous development.

iv. Ecology correspondence: Autonomous development construction is based on ecology correspondence design and reduction principle.

(8) Administration and maintenance

i. Life rule: Community rules are established to promote the execution.

ii. Subdivision management: Maintenance and management systems are available in communities to divide responsible areas.

iii. Maintenance reliability: Communities present the work of reliable maintenance and management.

\subsection{Test Method}

To improve blighted space in national rural communities identified by the Soil and Water Conservation Bureau (SWCB), the Council of Agriculture in 2012-2014, a total of 52 awarded communities and relevant teams, tutors, committees, and case officers were selected for this study. The 10 experts were chosen from the tutors, committees, and officers of SWCB. Random sampling was used to select 10 communities from the above 52 awarded communities, and three samples were selected among community leaders and residents in these 10 communities. A total of 30 questionnaires were collected, and 30 questionnaires were collected for the community data analysis.

\section{Results and Discussion}

AHP is used to study the key success factors in autonomous landscape development of rural communities in Taiwan. The weight and priority are calculated and sequenced, and the mechanism is established to evaluate the autonomous community development criteria and elements. The priority of key success factors in autonomous development of rural communities could provide a reference for communities practicing autonomous development as well as employment and purchase in the future.

\subsection{Expert Data Analysis}

C.I. and C.R. are used to test the pairwise comparison matrix consistency of experts' questionnaire survey results (Table 3). When C.I. $<0.1$, the consistency of the questionnaire respondents' evaluation is acceptable; otherwise, the result is inconsistent. When C.R. $<0.1$, the pairwise comparison matrix consistency is satisfactory; otherwise, the pairwise comparison matrix consistency does not achieve satisfactory and acceptable reliability. 
Table 3. Expert questionnaire survey result.

\begin{tabular}{ccc}
\hline Expert & Consistence Index C.I. & Consistence Ratio C.R. \\
\hline 1 & 0.0573 & 0.0737 \\
2 & 0.0737 & 0.0995 \\
3 & 0.0470 & 0.0625 \\
4 & 0.0508 & 0.0732 \\
5 & 0.0613 & 0.0804 \\
6 & 0.0700 & 0.0998 \\
7 & 0.0690 & 0.0902 \\
8 & 0.0071 & 0.0009 \\
9 & 0.0161 & 0.0213 \\
10 & 0.0516 & 0.0712 \\
\hline
\end{tabular}

Table 4 shows the results from the experts' questionnaire survey. The C.R. of 10 experts and scholars is $<0.1$, thereby indicating satisfactory pairwise comparison matrix consistency and acceptable reliability, thus indicating an effective questionnaire.

Table 4. Expert questionnaire passing hierarchical consistency test value.

\begin{tabular}{|c|c|c|c|}
\hline Criterion & Test Value & Sub-Criterion & Test Value \\
\hline Geographic location & \multirow{8}{*}{$\begin{array}{l}\text { C.I. }=0.0051 \\
\text { C.R. }=0.0067\end{array}$} & $\begin{array}{l}\text { Comprehensive planning }{ }^{1} \\
\text { Development priority } \\
\text { Scenic spot concatenation } \\
\text { Located in settlement }\end{array}$ & $\begin{array}{l}\text { C.I. }=0.0031 \\
\text { C.R. }=0.0035\end{array}$ \\
\hline Function and benefits & & $\begin{array}{l}\text { Interior consensus } \\
\text { Landscaping } \\
\text { Functioning } \\
\text { Public use }\end{array}$ & $\begin{array}{l}\text { C.I. }=0.0812 \\
\text { C.R. }=0.0903\end{array}$ \\
\hline Feature integration & & $\begin{array}{l}\text { Performance focus } \\
\text { Cultural integration } \\
\text { Feature display }\end{array}$ & $\begin{array}{l}\text { C.I. }=0.0034 \\
\text { C.R. }=0.0059\end{array}$ \\
\hline Culture and art & & $\begin{array}{l}\text { Cultural connotation } \\
\text { Art show } \\
\text { Skill heritage }\end{array}$ & $\begin{array}{l}\text { C.I. }=0.0206 \\
\text { C.R. }=0.0355\end{array}$ \\
\hline Manpower input & & $\begin{array}{c}\text { Leading cadre } \\
\text { Art expert } \\
\text { Workman implementation } \\
\text { Volunteer participation }\end{array}$ & $\begin{array}{l}\text { C.I. }=0.0053 \\
\text { C.R. }=0.0058\end{array}$ \\
\hline Technical expertise & & $\begin{array}{c}\text { Skilled technique } \\
\text { Construction quality } \\
\text { Ancient technique integration }\end{array}$ & $\begin{array}{l}\text { C.I. }=0.0234 \\
\text { C.R. }=0.0404\end{array}$ \\
\hline Creative development & & $\begin{array}{l}\text { Local material } \\
\text { Recycle and reuse } \\
\text { Creative invention } \\
\text { Ecology correspondence }\end{array}$ & $\begin{array}{l}\text { C.I. }=0.0057 \\
\text { C.R. }=0.0063\end{array}$ \\
\hline Administration and maintenance & & $\begin{array}{c}\text { Life rule } \\
\text { Subdivision management } \\
\text { Maintenance reliability }\end{array}$ & $\begin{array}{l}\text { C.I. }=0.0156 \\
\text { C.R. }=0.0269\end{array}$ \\
\hline
\end{tabular}

\footnotetext{
1 Here, comprehensive planning refers to locating in the core settlement of the rural rejuvenation
} comprehensive planning.

The hierarchical consistency test result of the expert questionnaire is shown in Table 5. The consistency test between the criteria of "geographic location", "function and benefits", "feature integration", "culture and art", "manpower input", "technical expertise", "creative invention", and "administration and maintenance" and the pairwise comparison matrix of the target hierarchy of "key 
success factors in autonomous landscape development of rural communities" obtains C.I. $=0.0051$ and C.R. $=0.0067$, which are both less than 0.1.

Table 5. Relative weight of criteria.

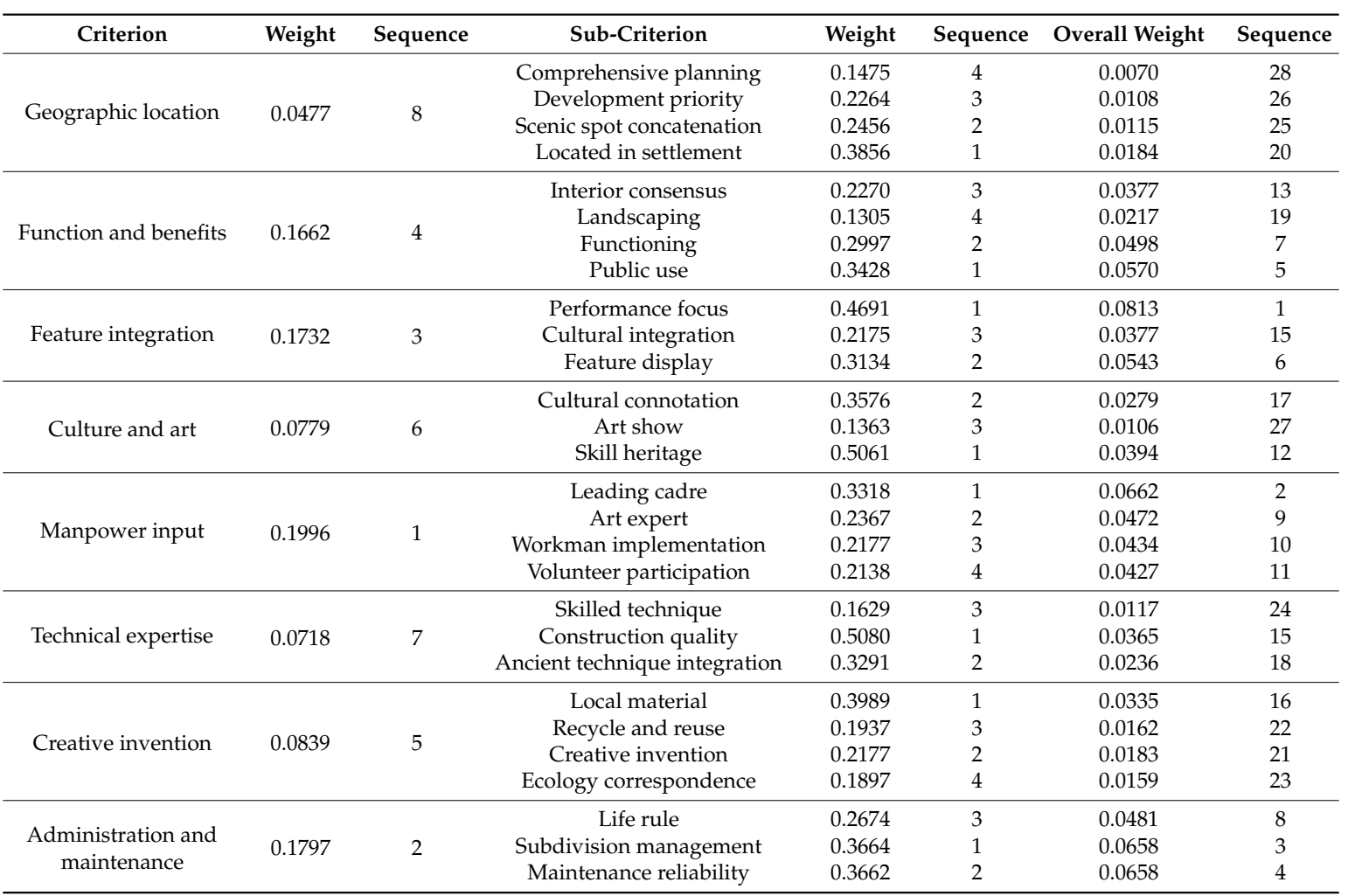

With the use of the previous equations to calculate the element weights in different hierarchies and the consistency test, the analyses proceed as follows: first, for the pairwise comparison matrix of the eight criteria of "geographic location", "function and benefits", "feature integration", "culture and art", "manpower input", "technical expertise", "creative invention", and "administration and maintenance" and the target hierarchy "key success factors in autonomous landscape development of rural communities", the weights are analyzed (Table 4). The element weights of criteria are multiplied by the relative weight of the corresponding elements of the sub-criteria to calculate the total weight of such elements to the target hierarchy "key success factors in autonomous landscape development of rural communities". The sequence of elements of sub-criteria in the overall evaluation is shown.

Experts regard the weights of success factors in rural communities with autonomous landscape development and find that "performance focus", "leading cadre", and "subdivision management" belong to "feature integration", "manpower input", and "administration and maintenance". Such a result shows that experts regard "manpower input", "feature integration", and "administration and maintenance" as the key success factors in communities with autonomous development. "Manpower input" is consistent with Liang's study [23], "administration and maintenance" conforms to the research results of $\mathrm{Wu}$ and Chen [24], and "feature integration" agrees with Xu's research results [25].

\subsection{Community Resident Data Analysis}

Table 6 shows the test of the rural community questionnaire result. The C.R. of 30 community residents is $<0.1$, thereby indicating satisfactory pairwise comparison matrix consistency and acceptable reliability, and thus is an effective questionnaire. 
Table 6. Community questionnaire survey results.

\begin{tabular}{cccccc}
\hline $\begin{array}{c}\text { Community } \\
\text { No. }\end{array}$ & $\begin{array}{c}\text { Consistence } \\
\text { Index C.I. }\end{array}$ & $\begin{array}{c}\text { Consistence } \\
\text { Ratio C.R. }\end{array}$ & $\begin{array}{c}\text { Community } \\
\text { No. }\end{array}$ & $\begin{array}{c}\text { Consistence } \\
\text { Index C.I. }\end{array}$ & $\begin{array}{c}\text { Consistence } \\
\text { Ratio C.R. }\end{array}$ \\
\hline 1 & 0.0710 & 0.0974 & 16 & 0.0250 & 0.0330 \\
2 & 0.0743 & 0.0995 & 17 & 0.0378 & 0.0483 \\
3 & 0.0450 & 0.0606 & 18 & 0.0747 & 0.0980 \\
4 & 0.0678 & 0.0957 & 19 & 0.0123 & 0.0161 \\
5 & 0.0397 & 0.0526 & 20 & 0.0161 & 0.0207 \\
6 & 0.0226 & 0.0304 & 21 & 0.0615 & 0.0816 \\
7 & 0.0302 & 0.0397 & 22 & 0.0771 & 0.0989 \\
8 & 0.0732 & 0.0988 & 23 & 0.0559 & 0.0733 \\
9 & 0.0621 & 0.0800 & 24 & 0.0088 & 0.0113 \\
10 & 0.0405 & 0.0525 & 25 & 0.0204 & 0.0261 \\
11 & 0.0041 & 0.0053 & 26 & 0.0225 & 0.0293 \\
12 & 0.0240 & 0.0309 & 27 & 0.0639 & 0.0827 \\
13 & 0.0048 & 0.0062 & 28 & 0.0649 & 0.0859 \\
14 & 0.0728 & 0.0988 & 29 & 0.0131 & 0.0170 \\
15 & 0.0589 & 0.0763 & 30 & 0.0147 & 0.0189 \\
\hline
\end{tabular}

The consistency test result of rural community residents is shown in Table 7. The consistency test of the pairwise comparison matrix between the criteria of "geographic location", "function and benefits", "feature integration", "culture and art", "manpower input", "technical expertise", "creative invention", and "administration and maintenance" and the target hierarchy of "key success factors in autonomous development of rural landscape" obtains C.I. $=0.0011$ and C.R. $=0.0015$, which are both less than 0.1 .

Table 7. Community resident questionnaire passing hierarchical consistency test value.

\begin{tabular}{|c|c|c|c|}
\hline Criterion & Test Value & Sub-Criterion & Test Value \\
\hline Geographic location & \multirow{8}{*}{$\begin{array}{l}\text { C.I. }=0.0011 \\
\text { C.R. }=0.0015\end{array}$} & $\begin{array}{l}\text { Comprehensive planning } \\
\text { Development priority } \\
\text { Scenic spot concatenation } \\
\text { Located in settlement }\end{array}$ & $\begin{array}{l}\text { C.I. }=0.0042 \\
\text { C.R. }=0.0046\end{array}$ \\
\hline Function and benefits & & $\begin{array}{l}\text { Interior consensus } \\
\text { Landscaping } \\
\text { Functioning } \\
\text { Public use }\end{array}$ & $\begin{array}{l}\text { C.I. }=0.0119 \\
\text { C.R. }=0.0259\end{array}$ \\
\hline Feature integration & & $\begin{array}{l}\text { Performance focus } \\
\text { Cultural integration } \\
\text { Feature display }\end{array}$ & $\begin{array}{l}\text { C.I. }=0.0150 \\
\text { C.R. }=0.0259\end{array}$ \\
\hline Culture and art & & $\begin{array}{l}\text { Cultural connotation } \\
\text { Art show } \\
\text { Skill heritage }\end{array}$ & $\begin{array}{l}\text { C.I. }=0.0429 \\
\text { C.R. }=0.0740\end{array}$ \\
\hline Manpower input & & $\begin{array}{c}\text { Leading cadre } \\
\text { Art expert } \\
\text { Workman implementation } \\
\text { Volunteer participation } \\
\end{array}$ & $\begin{array}{l}\text { C.I. }=0.0235 \\
\text { C.R. }=0.0261\end{array}$ \\
\hline Technical expertise & & $\begin{array}{c}\text { Skilled technique } \\
\text { Construction quality } \\
\text { Ancient technique integration }\end{array}$ & $\begin{array}{l}\text { C.I. }=0.0113 \\
\text { C.R. }=0.0195\end{array}$ \\
\hline Creative development & & $\begin{array}{c}\text { Local material } \\
\text { Recycle and reuse } \\
\text { Creative invention } \\
\text { Ecology correspondence }\end{array}$ & $\begin{array}{l}\text { C.I. }=0.0032 \\
\text { C.R. }=0.0036\end{array}$ \\
\hline Administration and maintenance & & $\begin{array}{c}\text { Life rule } \\
\text { Subdivision management } \\
\text { Maintenance reliability }\end{array}$ & $\begin{array}{l}\text { C.I. }=0.0156 \\
\text { C.R. }=0.0268\end{array}$ \\
\hline
\end{tabular}


Similarly, the element weight and consistency test in various hierarchies are calculated with previous equations. The analyses are explained as follows: for the pairwise comparison matrix between the criteria elements of "geographic location", "function and benefits", "feature integration", "culture and art", "manpower input", "technical expertise", "creative invention", and "administration and maintenance" and the target hierarchy of "key success factors in autonomous development of rural landscape" of community residents, the weights are analyzed (Table 8). The element weights in the criteria are multiplied by the relative weights of the corresponding elements in the sub-criteria to calculate the total weight of the factors in the target hierarchy of "key success factors in autonomous landscape development of rural communities". The sequence of the sub-criteria elements in the overall evaluation is further presented.

Table 8. Relative weight and sequence of hierarchical factors.

\begin{tabular}{|c|c|c|c|c|c|c|c|}
\hline Criterion & Weight & Sequence & Sub-criterion & Weight & Sequence & Overall weight & Sequence \\
\hline \multirow{4}{*}{ Geographic location } & \multirow{4}{*}{0.0424} & \multirow{4}{*}{8} & Comprehensive planning & 0.1256 & 4 & 0.0053 & 28 \\
\hline & & & Development priority & 0.2416 & 3 & 0.0102 & 26 \\
\hline & & & Scenic spot concatenation & 0.2832 & 2 & 0.0120 & 24 \\
\hline & & & Located in settlement & 0.3496 & 1 & 0.0148 & 22 \\
\hline \multirow{4}{*}{ Function and benefits } & \multirow{4}{*}{0.2096} & \multirow{4}{*}{2} & Interior consensus & 0.2587 & 2 & 0.0542 & 5 \\
\hline & & & Landscaping & 0.1105 & 4 & 0.0232 & 19 \\
\hline & & & Functioning & 0.2583 & 3 & 0.0542 & 6 \\
\hline & & & Public use & 0.3725 & 1 & 0.0781 & 2 \\
\hline \multirow{3}{*}{ Feature integration } & \multirow{3}{*}{0.1629} & \multirow{3}{*}{3} & Performance focus & 0.5572 & 1 & 0.0908 & 1 \\
\hline & & & Cultural integration & 0.2181 & 3 & 0.0355 & 14 \\
\hline & & & Feature display & 0.2247 & 2 & 0.0366 & 12 \\
\hline \multirow{3}{*}{ Culture and art } & \multirow{3}{*}{0.0625} & \multirow{3}{*}{7} & Cultural connotation & 0.3649 & 2 & 0.0228 & 20 \\
\hline & & & Art show & 0.1286 & 3 & 0.0080 & 27 \\
\hline & & & Skill heritage & 0.5065 & 1 & 0.0317 & 16 \\
\hline \multirow{4}{*}{ Manpower input } & \multirow{4}{*}{0.2190} & \multirow{4}{*}{1} & Leading cadre & 0.2420 & 2 & 0.0530 & 7 \\
\hline & & & Art expert & 0.3446 & 1 & 0.0755 & 3 \\
\hline & & & Workman implementation & 0.2269 & 3 & 0.0497 & 8 \\
\hline & & & Volunteer participation & 0.1865 & 4 & 0.0408 & 10 \\
\hline \multirow{3}{*}{ Technical expertise } & \multirow{3}{*}{0.0704} & \multirow{3}{*}{6} & Skilled technique & 0.1488 & 3 & 0.0105 & 25 \\
\hline & & & Construction quality & 0.4511 & 1 & 0.0318 & 15 \\
\hline & & & Ancient technique integration & 0.4000 & 2 & 0.0282 & 17 \\
\hline \multirow{4}{*}{ Creative invention } & \multirow{4}{*}{0.0943} & \multirow{4}{*}{5} & Local material & 0.3841 & 1 & 0.0362 & 13 \\
\hline & & & Recycle and reuse & 0.1936 & 3 & 0.0183 & 21 \\
\hline & & & Creative invention & 0.2811 & 2 & 0.0265 & 18 \\
\hline & & & Ecology correspondence & 0.1412 & 4 & 0.0133 & 23 \\
\hline \multirow{3}{*}{$\begin{array}{l}\text { Administration and } \\
\text { maintenance }\end{array}$} & \multirow{3}{*}{0.1387} & \multirow{3}{*}{4} & Life rule & 0.2655 & 3 & 0.0368 & 11 \\
\hline & & & Subdivision management & 0.3973 & 1 & 0.0552 & 4 \\
\hline & & & Maintenance reliability & 0.3372 & 2 & 0.0468 & 9 \\
\hline
\end{tabular}

Given the weights of success factors in rural communities with autonomous landscape development, rural community residents consider that "performance focus", "public use", and "art expert" belong to "feature integration", "function and benefits", and "manpower input". This result reveals that community residents consider "manpower input", "feature integration", and "function and benefits" as the key success factors in communities with autonomous development. "Manpower input" is consistent with Liang's research [23], "feature integration" agrees with Xu's results [25], and "function and benefits" conforms to research results $[24,26]$.

According to the overall weight and order in Table 8, the top three success factors in autonomous landscape development in rural communities are "manpower input" (0.2190), "function and benefits" (0.2096), and "feature integration" (0.1629). AHP indicates that experts, community cadres, and residents in this study regard manpower input as the critical success factors in autonomous landscape development in rural communities. The results reveal that rural communities have to follow the instruction of leading cadres in communities, call for volunteers, include community workers, and involve community art experts in rural autonomous development to achieve the maximum effect. 
According to the weights in the second hierarchy, the experts consider "performance focus" (0.0813) as the most important criterion, followed by "leading cadre" (0.0662) and "subdivision management" (0.0658). However, "comprehensive planning" (0.0070) is lower, thereby revealing that the selection of autonomous development locations is not significantly correlated with rural rejuvenation comprehensive planning. The community residents also regard "performance focus" (0.0908) as the most important factor, followed by "public use" (0.0781) and "art expert" (0.0755), thereby showing that experts and community residents agree that the content of autonomous development should conform to the local rural development focus.

Numerous key success factors are needed in the autonomous development of rural communities. A complete key success factor evaluation model is constructed in this study for the reference of communities practicing autonomous development. For example, communities used to emphasize appearance after construction. Among the key success factors in the long-term community interviews, "manpower input" has the highest weight, thereby revealing that a community that invests considerably in human resources, including leading cadres, art experts, community workers, and volunteers, when practicing autonomous development to cohere to community residents' consensus and generate emotion, could enhance the effect of autonomous community development.

For instance, Pinghe Community in Dacun Township, Changhua County, combines construction with local red bricks with art to create a unique appearance. Moreover, using red bricks for construction supports the local brick factory, thereby creating a win-win situation between the local industry and the community itself $[23,42]$.

The rural areas of Taiwan are often weaker than urban ones. There are relatively more pockets with a poorly functioning economy, a dirty environment, unhealthy conditions, and dilapidated buildings seen in rural areas. Through the efforts of governments, community organizations, and professional teachers, rural environment and the quality of the functioning of communities have improved significantly (Figure 3). From 2011 to 2015, there were 558 communities in Taiwan that participated in the project (NT \$140 million, equivalent to US $\$ 4.67$ million), and then an annual expenditure of NT \$1.25 billion (equivalent to US \$1.67 million) per year will continue to improve rural areas in the future. The project is expected to last for five years, until 2020.

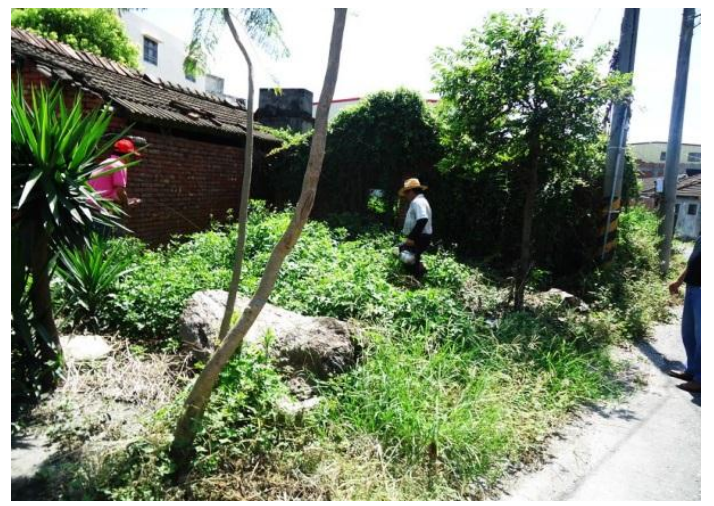

(a)

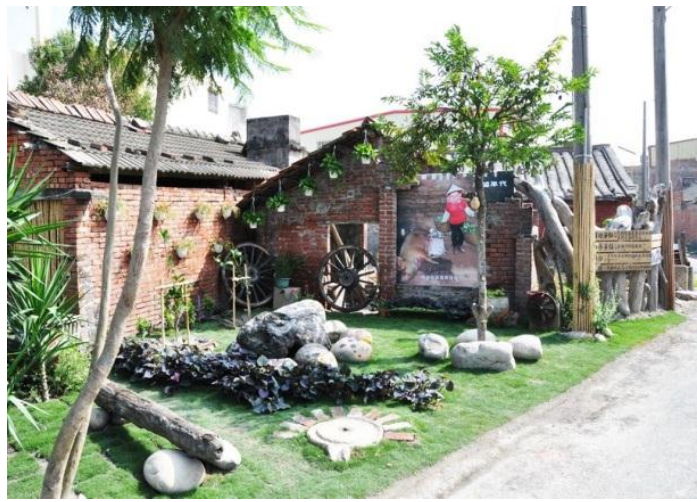

(b)

Figure 3. Residents themselves participate in rural living environment work in A-Quan Community, Yunlin County: (a) before; (b) after.

Figure 4 shows the area for urban planning in Taiwan. Red areas indicate urban areas (around $4750 \mathrm{~km}^{2}$ ), and the rural areas are outside the red areas (around $31,250 \mathrm{~km}^{2}$ ), accounting for $86.8 \%$ of the total area of Taiwan. There are 4232 rural communities, and 2511 communities are involved in the Rural Regeneration Plan (59.3\%) as of 26 April 2017; 578 rural communities (13.7\%) have completed their self-created training and proposed their future vision programs. 


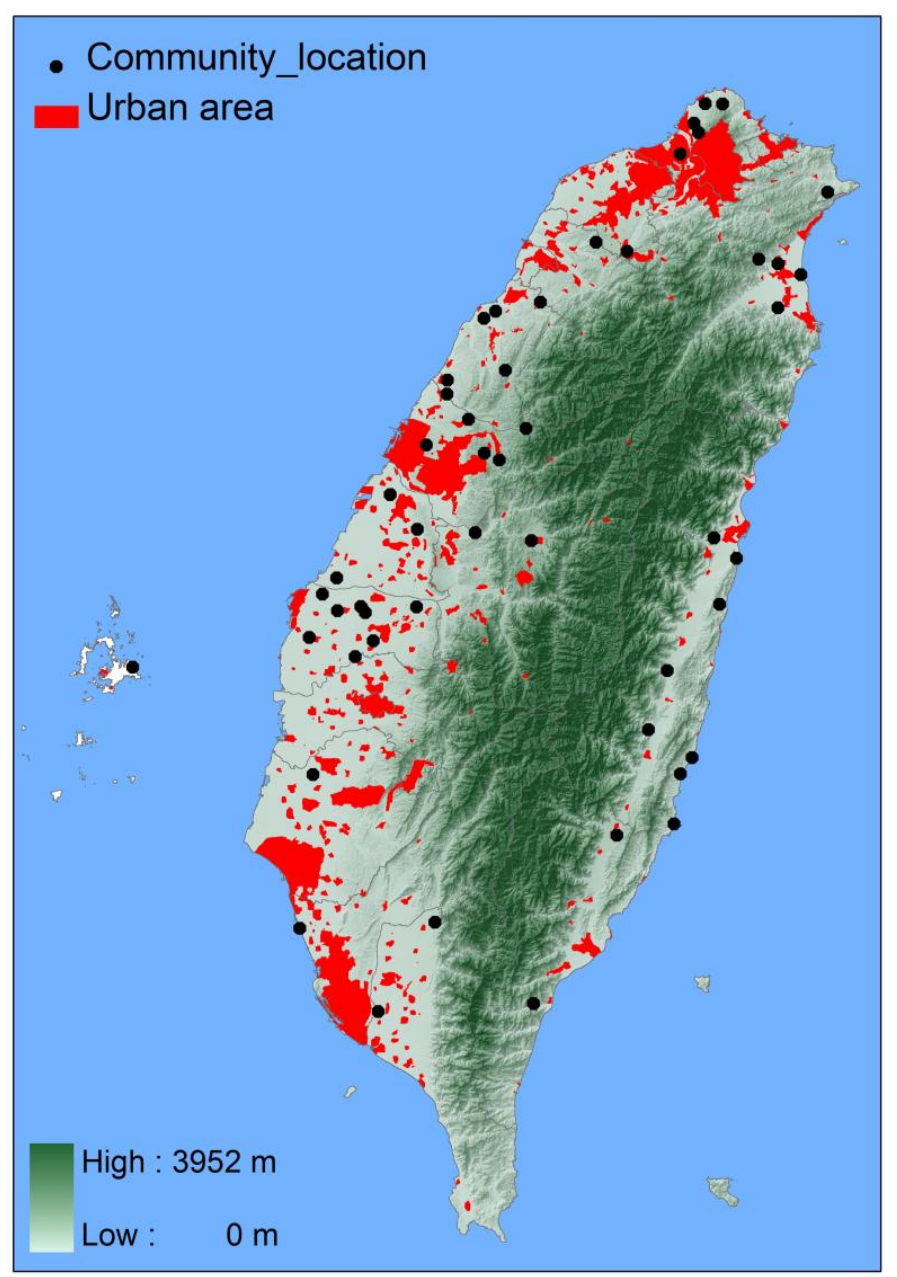

Figure 4. Urban planning areas in Taiwan: the dots represent the 52 communities of this study (source: Construction and Planning Agency, Ministry of the Interior, Taiwan).

Although laws and regulations, methods of community self-construction, and objectives are different in different regions of the country, the principles of bottom-up participation, self-planning and co-participation, and government subsidy and support will be similar. The methods proposed in this study can be applied in many democratic countries. Using the participation of the residents, democratic methods of interaction, discussion of the needs of their own community, and their own community proposals, community residents can apply for funding from the government to make the ideal of community construction real, which is the most valuable power of the people in a democratic country or even a democratic community.

\section{Conclusions}

Through a literature review and discussion with experts and scholars, a hierarchical structure with a target hierarchy, 8 criteria, and 28 sub-criteria is established. AHP is applied to calculate and organize the relative weights of factors in various hierarchies. A questionnaire survey among experts, scholars, and community residents indicates that "manpower input" is considered the most important key success factor in the autonomous landscape development of rural communities. This finding reveals that rural communities should follow the instruction of leading cadres, and enlist the help of volunteers, workers, and art experts for enhanced autonomous development.

Experts and scholars also regard "performance focus" as the most important factor, followed by "leading cadre" and "subdivision management". They agree less with regard to "comprehensive planning", 
thereby showing that selecting the place in the core settlement of rural rejuvenation for autonomous development is not particularly relevant. Residents also agree with the importance of "performance focus", thereby showing that experts, scholars, and residents consider that autonomous development should correspond to the rural development focus. This factor is followed by "public use" and "art expert".

Moreover, experts, scholars, and residents regard "geographic location" as the least important factor, with weights of 0.0070 and 0.0053 . The sub-criteria of "comprehensive planning", "development priority", "scenic spot concatenation", and "located in settlement" also show low importance. Accordingly, whether "geographic location" for autonomous community development is connected with surrounding tourist spots or located in the core settlement of rural rejuvenation is unimportant. Experts and community residents have different viewpoints on key success factors, but their opinions tend to be consistent.

Acknowledgments: This is a translation/reprint of "Using AHP on the Successful Factors Examine of Autonomous Landscape Development in Rural Communities" originally published in Chinese by Journal of National Formosa University, 2016, volume 33, issue 3, pp. 71-87. This translation was prepared by Ta-Ching Liang and Szu-Hsien Peng. Permission was granted by Journal of National Formosa University, National Formosa University, and the authors. We thank Ming-Yang Wu, a graduate of the Department of Leisure and Recreation at National Formosa University, who assisted in the investigation and analysis of the questionnaire task.

Author Contributions: Ta-Ching Liang and Szu-Hsien Peng conceived and designed the research method. Ta-Ching Liang performed the investigation and analyzed the data, and Szu-Hsien Peng wrote the paper.

Conflicts of Interest: The authors declare no conflict of interest.

\section{References}

1. Liu, C.Z.; Lai, Y.S. A study on village renewal and community reconstruction. Rural Dev. Perspect. 2012, $14,60-89$.

2. Hsieh, H.C. Dilemma and response on transformation of rural community industry in Taiwan. Newsl. Res. Appl. Ethics 2002, 23, 32-36.

3. Howley, P. Landscape aesthetics: Assessing the general publics' preferences towards rural landscapes. Ecol. Econ. 2011, 72, 161-169. [CrossRef]

4. Van der Vaart, J.H. Towards a new rural landscape: Consequences of non-agricultural re-use of redundant farm buildings in Friesland. Landsc. Urban Plan. 2005, 70, 143-152. [CrossRef]

5. García, A.I.; Ayuga, F. Reuse of abandoned buildings and the rural landscape: The situation in Spain. Trans. ASABE 2007, 50, 1383-1394. [CrossRef]

6. Hernández, J.; Garcia, L.; Ayuga, F. Integration methodologies for visual impact assessment of rural buildings by geographic information systems. Biosyst. Eng. 2004, 88, 255-263. [CrossRef]

7. García, L.; Hernández, J.; Ayuga, F. Analysis of the materials and exterior texture of agro-industrial buildings: A photo-analytical approach to landscape integration. Landsc. Urban Plan. 2006, 74, 110-124. [CrossRef]

8. Kaplan, A.; Taşkın, T.; Önenç, A. Assessing the visual quality of rural and urban-fringed landscapes surrounding livestock farms. Biosyst. Eng. 2006, 95, 437-448. [CrossRef]

9. Long, H.; Liu, Y.; Wu, X.; Dong, G. Spatio-temporal dynamic patterns of farmland and rural settlements in $\mathrm{Su}-\mathrm{Xi-Chang} \mathrm{region:} \mathrm{Implications} \mathrm{for} \mathrm{building} \mathrm{a} \mathrm{new} \mathrm{countryside} \mathrm{in} \mathrm{coastal} \mathrm{China.} \mathrm{Land} \mathrm{Use} \mathrm{Policy} \mathrm{2009,}$ 26, 322-333. [CrossRef]

10. Dewey, J. Art as experience (New York: Capricorn, 1958). Hereafter ART 1934, 21, 75-78.

11. Höpfl, H.; Linstead, S. The Aesthetics of Organization; Sage Publications Limited: Thousand Oaks, CA, USA, 2000.

12. Muratet, A.; Pellegrini, P.; Dufour, A.-B.; Arrif, T.; Chiron, F. Perception and knowledge of plant diversity among urban park users. Landsc. Urban Plan. 2015, 137, 95-106. [CrossRef]

13. Shen, L.; Jiang, S.; Yuan, H. Critical indicators for assessing the contribution of infrastructure projects to coordinated urban-rural development in China. Habitat Int. 2012, 36, 237-246. [CrossRef]

14. Tuch, A.N.; Roth, S.P.; HornbæK, K.; Opwis, K.; Bargas-Avila, J.A. Is beautiful really usable? Toward understanding the relation between usability, aesthetics, and affect in HCI. Comput. Hum. Behav. 2012, 28, 1596-1607. [CrossRef]

15. Zhang, J.W.; Piff, P.K.; Iyer, R.; Koleva, S.; Keltner, D. An occasion for unselfing: Beautiful nature leads to prosociality. J. Environ. Psychol. 2014, 37, 61-72. [CrossRef] 
16. Gladkova, A.; Romero-Trillo, J. Ain't it beautiful? The conceptualization of beauty from an ethnopragmatic perspective. J. Pragmat. 2014, 60, 140-159. [CrossRef]

17. Liu, H.K. Landscape Aesthetics; China Forestry Press: Beijing, China, 2012.

18. Antrop, M.; Van Eetvelde, V. Holistic aspects of suburban landscapes: Visual image interpretation and landscape metrics. Landsc. Urban Plan. 2000, 50, 43-58. [CrossRef]

19. Antrop, M. Landscape change and the urbanization process in Europe. Landsc. Urban Plan. 2004, 67, 9-26. [CrossRef]

20. Hsu, C.F.; Sun, H.C. Study on the improvement of rural facade. Urban Constr. Theory Res. 2014, $22,810-811$.

21. Antrop, M. Background concepts for integrated landscape analysis. Agric. Ecosyst. Environ. 2000, 77, 17-28. [CrossRef]

22. Arriaza, M.; Cañas-Ortega, J.; Canas-Madueno, J.; Ruiz-Aviles, P. Assessing the visual quality of rural landscapes. Landsc. Urban Plan. 2004, 69, 115-125. [CrossRef]

23. Liang, T.C. Study on landscape features and tourism planning on rural area in scale of town level-A case of Fenyuan Village. J. Soil Water Conserv. Technol. 2008, 3, 212-220.

24. Wu, C.H.; Chen, K.H. Factors assessment of using constructed wetlands for treatment of domestic wastewater from rural communities. Chna Nan Annu. Bull. 2009, 35, 127-140.

25. $\mathrm{Xu}, \mathrm{W}$. Establishment of development model of rural greenway in Zhejiang. City Plan. Rev. 2010, 34, 61-64.

26. Chang, K.F.; Chou, P.C. A study on adapting the sustainable concept for the assessment system of the rural village in Pintung County. J. Inter. Archit. Des. 2011, 12, 23-34.

27. Huang, B.S. Exploring Value Creation of Public-Private Partnerships: A Case Study of Creative Industry; National Cheng Kung University: Tainan, Taiwan, 2013.

28. Wang, S.J.; Zhai, T.J. An action research on community participation of nankan riverfront environment improvement. J. Des. Res. 2013, 6, 21-32.

29. McCutcheon, R. Employment creation in public works: Labour-intensive construction in sub-saharan africa: The implications for South Africa. Habitat Int. 1995, 19, 331-355. [CrossRef]

30. Ares, R.; Fuentes, J.M.; Gallego, E.; Ayuga, F.; García, A.I. Use of the labour-intensive method in the repair of a rural road serving an indigenous community in Jocotán (Guatemala). Sci. Eng. Ethics 2012, 18, 315-338. [CrossRef] [PubMed]

31. Daniel, D.R. Management information crisis. Harv. Bus. Rev. 1961, 39, 111-121.

32. Glueck, W.F. Business Policy: Strategy Formation and Management Action; McGraw-Hill: New York, NY, USA, 1972.

33. Tilles, S. How to evaluate corporate strategy; Harvard Business Publishing: Brighton, MA, USA, 1963.

34. Wilson, J.Q.; Kelling, G.L. The police and neighborhood safety: Broken windows. Atl. Mon. 1982, 249, $29-38$.

35. Zeleny, M. Multiple criteria decision making: Eight concepts of optimality. Hum. Syst. Manag. 1998, 17, 97-107.

36. Nekhay, O.; Arriaza, M. How attractive is upland Olive Groves landscape? Application of the analytic hierarchy process and gis in southern spain. Sustainability 2016, 8, 1160. [CrossRef]

37. Song, B.; Sun, Q.; Li, Y.; Que, C. Evaluating the sustainability of community-based long-term care programmes: A hybrid multi-criteria decision making approach. Sustainability 2016, 8, 657. [CrossRef]

38. Wang, H.J.; Zeng, Z.T. A multi-objective decision-making process for reuse selection of historic buildings. Expert Syst. Appl. 2010, 37, 1241-1249. [CrossRef]

39. Jeong, J.S.; García-Moruno, L.; Hernández-Blanco, J. Integrating buildings into a rural landscape using a multi-criteria spatial decision analysis in GIS-enabled web environment. Biosyst. Eng. 2012, 112, 82-92. [CrossRef]

40. Saaty, T.L. How to make a decision: The analytic hierarchy process. Eur. J. Oper. Res. 1990, 48, 9-26. [CrossRef]

41. Saaty, T.L. On polynomials and crossing numbers of complete graphs. J. Comb. Theory Ser. A 1971, 10, $183-184$. [CrossRef]

42. Liang, T.C.; Chen, K.T.; Chang, C.P.; Chuang, H.Y. Study on tourism development and rural village types on hillside-a case as countryside of the belt area of basin Pu-Li. J. Soil Water Conserv. Technol. 2009, 4, 82-90.

(C) 2017 by the authors. Licensee MDPI, Basel, Switzerland. This article is an open access article distributed under the terms and conditions of the Creative Commons Attribution (CC BY) license (http:/ / creativecommons.org/licenses/by/4.0/). 